\title{
Abundance and distribution of Royle's Pika (Ochotona roylei) along different altitudinal ranges of Kedarnath Wildlife Sanctuary, Uttarakhand Himalayas, India
}

\author{
${ }^{1}$ Abdul Haleem, ${ }^{2}$ Orus Ilyas, ${ }^{3}$ Zarreen Syed, ${ }^{4}$ Sumit Kumar Arya \\ ${ }^{1,2,3,4}$ Department of Wildlife Sciences Aligarh Muslim University, Aligarh, UP, India
}

\begin{abstract}
Abundance and distribution of Royle's Pika (Ochotona roylei) was studied in a part of Kedarnath Wildlife Sanctuary, Uttarakhand Himalaya along altitudinal ranges from 2700 to $3600 \mathrm{~m}$ a.s.l. during premonsoon season of 2012. Different plots $(20 \times 20 \mathrm{~m})$ were marked with in each available habitat type and pikas were searched once in a week. The highest density of Pika was found in Tree-line region, along 3001-3300 m a.s.l. whereas the lowest density was found in alpine region, along 3301-3600 $\mathrm{m}$ a.s.l. Pika distribution was found to be highest in mixed habitat, north east aspect and under very high rock cover where as open habitat, east facing slope and low rock cover show lowest distribution.
\end{abstract}

Key-words: Density, Hay Pile, Kedarnath Wildlife Sanctuary, Royle's Pika, Uttarakhand

\section{Introduction}

Within 'the Order Lagomorpha, the pikas occupy a distinguished position by their mode of life and behaviour quite different from those of hares and rabbits. Pikas are small mammal weighing about 100-175 gram (Beever 2002), having rounded ears, short legs and devoid of tails. They have little longer front legs than the rear ones. Pikas are absolutely endemic to the Himalayas, the mountains and steppes of central Asia, and the mountains of North-western America (Prater 2005). They are having four incisors which make them differ from rodents having two incisors. Pikas are found to be relatively primitive animals, having passed their evolutionary zenith (Thenius 1972). Pikas are unique among alpine mammals in that they gather up vegetation throughout summer including flowers, grasses, leaves, evergreen needles, and even pine cones and live off the hay pile throughout winter, rather than hibernating or moving downslope (Holtcamp 2010). Various evidences have shown a good relation of livestock to pika's haypiles. Melnikov (1974) has stated that the domestic cows and horses generally locate Pika's haypiles and start feeding the hays deposited in there. According to Naumov (1974), shrews (Sorex sp.) which are insectivorous in their diet generally hunt Pika's haypiles in alpine region to feed upon insects present in there. Ochotona, the only living genus is adapted to alpine and subalpine habitats of North America and Asia. Paleoecological evidence suggests that pikas were far more widespread during the late Pleistocene in western North America than they are today (Grayson 1987). It is believed that there are about 16 species of Ochotona in the past which inhabited Africa and Europe (Thenius 1972). Currently there are 30 species found throughout the world, out of which 27are represented in India, including 7 species in the Indian Himalayan range (Hoffmann \& Smith 2005). Royal pika (Ochotona roylei), the fairly common species throughout Himalayan region (Hoffmann \& Smith 2005). Their body length ranges from 15 to $20 \mathrm{~cm}$ and the diameter of head is ca. $7 \mathrm{~cm}$ (Alfred et al. 2006). Pikas occur from $2500 \mathrm{~m}$ a.s.l to $5000 \mathrm{~m}$ a.s.l in western Himalaya (Bhattacharya et al. 2009), inhabiting open rocky ground and Rhododendron forests (Tak \& Lamba 1985). Their distribution is governed directly on the basis of availability of forage plant species (Kawamichi 1968).

There are number of fragmentary observations on ecology and ethology of pikas but few detailed work except those by Loukashkin (1940), Hayward (1952) and Haga (1960), apparently caused by their habitat preference for high altitudes or barren lands inaccessible to research workers. There are very few studies which have been conducted on Royle's pikas. They are mainly studied by Kawamichi (1968), Kawamichi (1971), Smith et al. (1990), and Bhattacharyya et al. (2009). The present study is also an attempt to understand status and distribution of Royle's pikas along different altitudinal range of Kedarnath wildlife sanctuary.

\subsection{Study area:}

\section{Material And Methods}

The study was carried out in a part of Kedarnath wildlife sanctuary (KWLS) located in the Garhwal region of Greater Himalaya in Uttarakhand $\left(30^{\circ} 25^{\circ} 00^{\prime \prime}-30^{\circ} 45^{\prime} \mathrm{N}\right.$ and $\left.78^{\circ} 55^{\prime} 00^{\prime \prime}-79^{\circ} 22^{\prime} 00^{\prime \prime} \mathrm{E}\right)$. The area covered by sanctuary is 97517.80 ha. (25293.70 ha. in Chamoli district and 72224.10 ha. in Rudraprayag district). The sanctuary lies in the upper catchment of the Alaknanda and Mandakini Rivers, which are major tributaries of Ganges, having altitudinal ranges from $1160 \mathrm{~m}$ a.s.l. to $7068 \mathrm{~m}$ a.s.l. The KWLS is influenced by south west 
monsoon in summer and by westerly disturbances in winter (Mani 1981). The monsoon reaches this PA by mid June and continues till end of September. Winter is experienced from December to March. The intensive study area is located in southern fringe of KWLS around Bhulkana, Shokhark and Tungnath. Quercus semecarpifolia, Rhododendron arborium, Rhododendron campanulatum and Abies pindrow are the major dominated tree species present in Bhulkana and Shokhark. The alpine meadows (Bugiyal) at and around Tungnath are dominated by different herbs species and Danthonia grassland (Sundriyal et al. 1987).

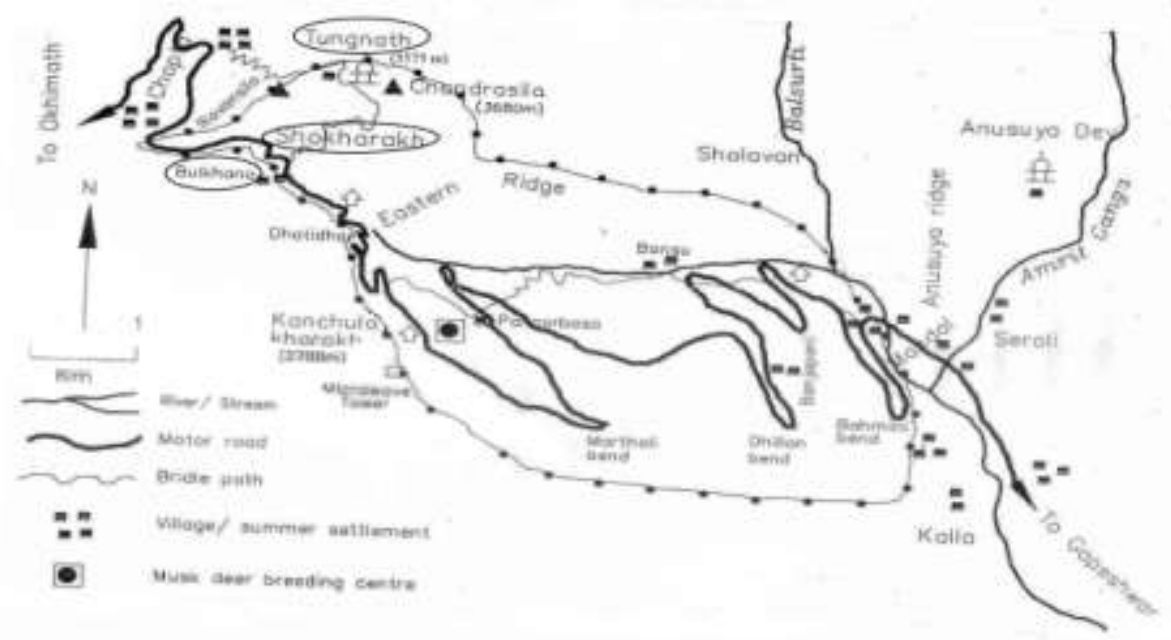

Fig: 1. Map of Kedarnath wildllife sanctuary pointing out study area (Source: THDC India Hydro electric project report 2011)

\subsection{Data collection:}

Data for assessing status and distribution of pikas were collected during pre-monsoon season of 2012. The study area was divided into three zones along different altitudinal range, viz sub-alpine, tree-line and alpine. In each zone different plots $(20 \times 20 \mathrm{~m})$ were marked with in each available habitat type (Rocky, open and mixed) and pikas were searched once in a week. The location of the each and every plot was recorded through a Global Positioning system (GPS, Gramin 72). Each plot was monitored for 2 hours and data was collected on parameters: Habitat, weather, aspect, rock cover, distance from nearest human habitation, number of individual, sex (Male, female and unknown) and age (Juvenile, sub-adult, adult and unknown).

Morphological features of pikas are used for identifications of age. The juveniles showed a regular light brown fur coat; medium sized sub-adults had very small black patches or moulting marks in the dorsal portion of their bodies and scar marks on one or both ears; adults showed prominent ear scar marks with blackish molting marks on their dorsal body surface ( Bhattacharya et al. 2009).

\subsection{Data analysis:}

The sightings of pikas at each sampling plot were used to calculate density (number of individual/ha). The density values of pikas from each sampling plot were added together to calculate mean density vis-à-vis different sites and habitat parameters. One way analysis of variance and multiple comparisons (Scheffe's) were used to test for significant differences in mean density of pikas vis-à-vis habitat type and habitat factors. All statistical tests were performed following Zar (1984) using computer programme SPSS 6.1 (Norusis 1994).

\section{RESULTS}

The mean density of Pika was found to be maximum (48.442 ind/ha.) in tree-line region and minimum (20.761 ind/ha.) in alpine region of KWLS. However results were not found to be significant (F2 $17=0.394$, P $>0.05$ ), (Table 1). The density of Pikas was also found different along different altitudinal ranges of KWLS. The mean density of Pikas was found to be maximum (60.55 ind/ha.) along 3001-3300 m altitude and minimum (14.82 ind/ha.) along 3301-3600 m altitude. However results were not found to be significant (F2 $17=1.322$, P $>0.05$ ). (Table 2).

The mean density of pikas was also found different as far as different parameters are concern vis-à-vis habitats, aspect and rock cover. The mean density of Pika was found maximum $(56.22 \pm 26.91)$ in mixed habitat followed by rocky area $(46.13 \pm 17.10)$ and minimum $(11.53 \pm 7.29)$ in open habitat however results were not found to be significant $(\mathrm{F} 217=1.20, \mathrm{P}>0.05)$ (Table3).

The mean density of Pika in different aspect were also calculated and it was found that the mean density of Pika was maximum in North east facing slope (103.80 \pm 69.20$)$ followed by North facing slope (51.90 \pm 41.18$)$, South east facing slope (29.65 \pm 15.89$)$, North west facing slope $(25.95 \pm 16.56)$ and minimum 
in East facing slope (23.06 \pm 23.06$)$, however results were not found to be significant $(\mathrm{F} 415=0.88, \mathrm{P}>0.05)$, (Fig. 2). The distribution of Pika is also governed by rock cover and it was found that the mean density of Pika was significantly higher $(138.40 \pm 34.60)$ in very high rock cover than in low rock cover $(15.72 \pm 7.17)$ (F3 16= 4.654, $\mathrm{P}<0.05)$ (Figure-3).

Table 1. Mean density \pm SE of Pikas in different region of KWLS

\begin{tabular}{|c|c|c|}
\hline S.No & Region & Mean Density \pm SE \\
\hline 1 & Sub-alpine & $41.52 \pm 20.176$ \\
\hline 2 & Tree-line & $48.44 \pm 22.00$ \\
\hline 3 & Alpine & $20.76 \pm 13.84$ \\
\hline
\end{tabular}

Table 2. Mean density \pm SE of Pikas along different altitudinal range of KWLS

\begin{tabular}{|c|c|c|}
\hline S.No & Altitude $(\mathrm{m})$. & Mean Density \pm SE \\
\hline 1 & $2700-3000$ & $41.52 \pm 20.176$ \\
\hline 2 & $3001-3300$ & $60.55 \pm 25.95$ \\
\hline 3 & $3301-3600$ & $14.82 \pm 10.29$ \\
\hline
\end{tabular}

Table 3. Mean Density \pm SE of Pika in different habitat of KWLS

\begin{tabular}{|c|c|c|}
\hline S.No & Habitat & Mean Density \pm SE \\
\hline 1 & Mixed & $56.22 \pm 26.91$ \\
\hline 2 & Open & $11.53 \pm 7.29$ \\
\hline 3 & Rocky & $46.13 \pm 17.10$ \\
\hline
\end{tabular}

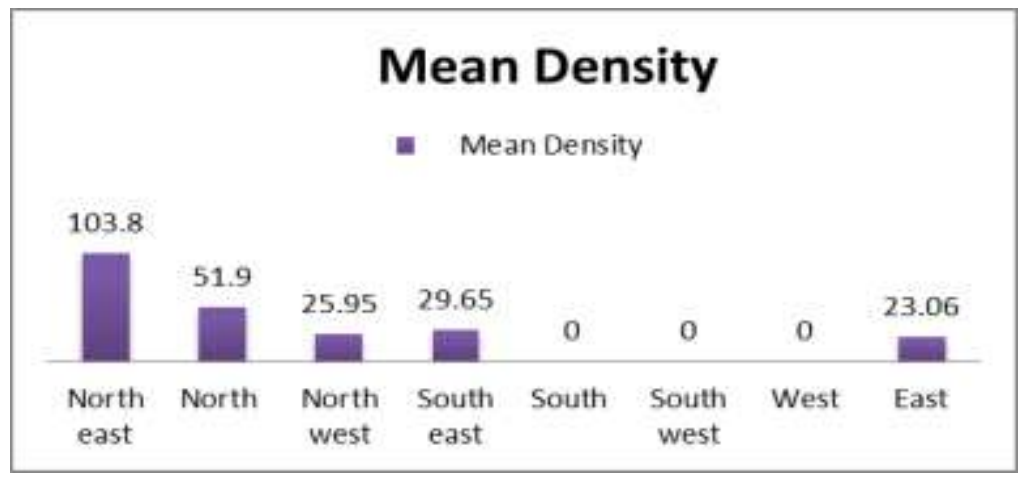

Fig: 2. Mean Density of Pika in different Aspect of KWLS

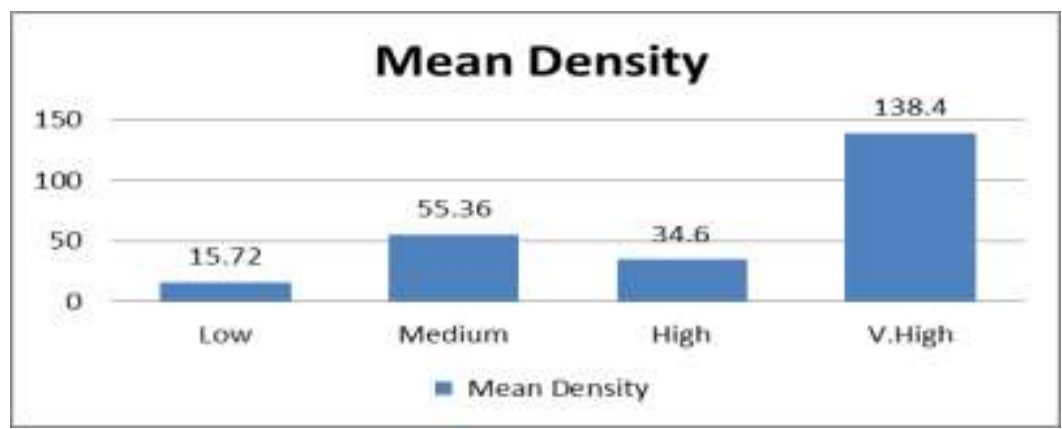

Fig: 3. Mean Density of Pika in different rock covers of KWLS

IV. DISCUSSION

Small mammals are an integral component of most ecosystems. Pika is one of the important species, if we loss them once then it will disturb the proper functioning of an ecosystem (Primack 1998). From the intensive study area Pika density was found higher than in Nepal Himalaya (12.5 ind/ha; Smith et al. 1990) and (15.3 ind/ha.; Bhattacharya et al. 2009). The reason could be the data was collected during pre-monsoon season only when they are not in hibernating and the samples size was relatively low as compare to rest studies. The mean density of pika was found to be maximum in tree line region and along 3001-3300 m altitude. The reason behind this could be that tree line region is largely inhabited by rocks and stones which govern the distribution of Pikas, as they get more escape from their predator and throughout winter season they feed on hay-piles, 
collected in summer under well covered shelter (Holtcamp 2010). Pikas also show different preference as far as habitat factors are concerns vis-à-vis, habitat, aspect and rock cover. Our results suggest that the amount of rock cover and the habitat are the two main factors, shaping the relative abundance of Royle's Pika population. The mean density of Pika was found maximum in mixed habitat than open and rocky area. The reason behind could be that the Pikas are mainly foraging species and they mainly feed on a variety of plants species and the mixed habitat are more rich and diverse as far as plants are concern. Likewise the mean density of Pika was found maximum under very high rock cover. The reason behind this could be that under the good rock cover they get proper shelter and during summer season when they collect hay-pile to feed on in winters, are well protected under good rock cover.

\section{Conclusion}

Being a very small mammal, this species has been ignored for long, so there is a pressing need for an intensive study of this species to understand the ecology and biology of the species, as the species is very important for the Himalayan ecosystem.

\section{Acknowledgements}

Authors are sincerely thankful to the forest department Gopeshwar, Chamoli, Uttarakhand for giving permission to carry out field work and their valuable support during the study. The help received from the local people during study is duly acknowledged. The authors are also thankful to Dr. Satish Kumar Associate Professor Dept. of Wildlife Sciences, A.M.U. Aligarh for reviewing the manuscript.

\section{References}

[1] E.A. Beever, Persistence of Pikas in two low elevation National monuments in the western united states, Park Science, 21 (2), 2002, 23-29.

[2] S.H. Prater, Book of Indian animals $3^{\text {rd }}$ edition (Bombay Natural History Society, Hornbill House Bombay, India, 2005).

[3] W. Holtcamp, Silence of the Pikas, Bio Science 60 (1), 2010, 8-12.

[4] R.S. Hoffmann and A.T. Smith, Lagomorphs. In: Wilson D.E. and Reeder D.M., (eds), Mammal Species of the world, $3^{\text {rd }}$ Edition (Johns Hopkins University Press, 2005) 185-211.

[5] S. Bhattacharya, B.S. Adhikari, and G.S Rawat, Abundance of Royle's Pika (Ochotona roylei) along an altitudinal gradient in Uttarakhand Western Himalaya, Hystrix Italian Journal of Mammalogy, 20(2), 2009, 111-119.

[6] J.R.B. Alfred, A.K. Das, and A.K. Sanyal, Animals of India: Mammals (Zoological Survey of India, 2006).

[7] P.C. Tak, and B.S. Lamba, Nanda Devi National Park: a contribution to its Mammalogy, Indian Journal of Forestry 8, 1985, 219230 .

[8] T. Kawamichi, Winter behaviour of the Himalayan pika. (Ochotona roylei), Journal of the faculty of Science, Hokkaido Univ. Ser. VI.Zool. 16, 1968, 582-594.

[9] R.C. Sundriyal, A.P. Joshi and R. Dhasmana, Phenology of high altitude plants at Tungnath in Central Himalaya, Tropical Ecology 28, 1987, 289-299.

[10] J.H. Zar, Biostatistical analysis (Prentice- Hall Inc., New Jersey, 1984) 